\section{Rapid Worsening of Esophageal Varices in a Patient with Small Hepatocellular Carcinomas after Percutaneous Ethanol Injection Therapy}

Y. Terui, H. Togashi, T. Matsuo, M. Aoki, Y. Takeda, T. Takeda, H. Mitsuhashi, H. Watanabe, K. Saito, T. Saito, T. Takahashi, H. Shinzawa

Second Department of Internal Medicine, Yamagata University School of Medicine, Yamagata, Japan

Corresponding Author

H. Togashi, M.D.

Second Dept. of Internal Medicine Yamagata University School of Medicine 2-2-2 lida-Nishi

Yamagata 990-9585

Japan

Fax: + 81-23-6285311

E-mail: htogashi@med.id.yamagata-u.ac.jp

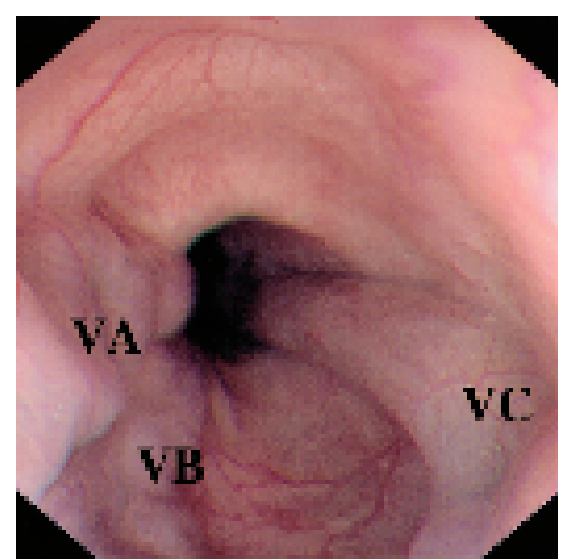

Figure 1 a,b A 64-year-old woman with liver cirrhosis $C$ was admitted to our hospital for the treatment of hepatocellular carcinomas (HCCs). Percutaneous ethanol injection therapy was performed for HCCs and complete tumor necrosis was achieved. A month after the final percutaneous ethanol injection, upper gastrointestinal endoscopy revealed exacerbation of the esophageal varices. The size and shape of the varices had enlarged remarkably and red spots were observed as indicated by the arrow heads. VA, varix $A$; VB, varix $B$; VC, varix $C$.

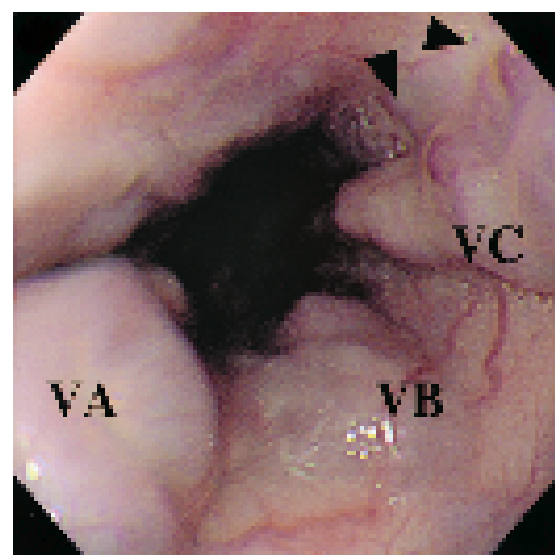

Figure $1 \mathbf{b}$ 